\title{
Preimplantation Genetic Diagnosis and Deafness
}

\author{
M. K. Taneja
}

Received: 12 May 2012/ Accepted: 12 June 2012/Published online: 30 June 2012

(C) Association of Otolaryngologists of India 2012

\begin{abstract}
Deafness in India ranges from $4.0 \%$ in urban and $4.0-11 \%$ in rural and slum areas, out of which $50 \%$ are of conductive hearing loss hence curable. In the congenital hearing loss the incidence of syndromic hearing loss is only $30 \%$, rest $70 \%$ are non syndromic. Genetic counseling is going to make aware the parents. Preimplantation genetic diagnosis can help to have a baby free from genetic deafness. Procedure is almost safe, harmless, non-invasive and ethically acceptable. While by genetic testing through prenatal genetic testing, amniocentesis and chorionic villous sampling is invasive and termination of pregnancy is difficult, social and ethical issue. The connexin 26 (CX26W 24X) has been observed as most common and easy to identify by polymerase chain reaction. There is always co morbidity after cochlear implantation and the person remains handicapped while baby after PGD shall be having healthy normal life and person prone to environmental factors may be counseled and guided to prevent deafness in next generation. Public must be made aware of noise pollution, tobacco toxicity and consanguinity. The obstetrician and pediatrician apart from ENT surgeon should be involved to prevent antenatal or neonatal deafness.
\end{abstract}

Keywords Sensoneural deafness - Preimplantation . Genetic diagnosis $\cdot$ National deafness programme

Though deafness is a global scenario but as per data available on an average $6.3 \%$ of the Indian population suffers from hearing loss which ranges from $4.0 \%$ in urban

M. K. Taneja ( $\varangle)$

E-982, Chitranjan Park, New Delhi 110019, India

e-mail: ijo_editor@rediffmail.com to $11.0 \%$ in rural and slum areas. For screening, preventing, counseling and curing deafness. It can be divided into two groups-conductive and sensoneural deafness. Conductive hearing loss is a mechanical defect in conduction from pinna to the external auditory canal, tympanic membrane, middle ear up to annular ligament at stapedeal foot plate (otosclerosis).

Sensoneural hearing loss is most commonly due to the involvement of sensory hair cells of the cochlea or sometimes of the auditory nerve or processing centre in the brain. About $50 \%$ of the patients with sensoneural deafness are congenitally deaf, and $30 \%$ of these congenitally deaf patients have syndromic deafness. More than 400 different syndromes are enlisted while $70 \%$ of congenital or hereditary deafness is non syndromic.

These syndromic or non syndromic hereditary deafness are due to faulty gene or interaction of genes.

To understand the basic one has to recapitulate, every cell of the body contains a complete set of gene (genome). There are about 30,000 genes and having two copies of each contained inside the chromosome. There are 23 pairs of chromosome out of which 22 pairs are same in male and female known as auto some. 23rd pair i.e. sex chromosomes (X or $\mathrm{Y})$ is different in male and female.

The alteration of gene known as mutation results in genetic disease. There are four ways by which gene can affect:

1. Autosomal recessive In majority of cases there is a second normal copy of altered gene which can come up and the altered gene remains as recessive but if the person gets second altered gene, the end result will be deafness. If only one altered copy is there person will be carrier and if both parents will have altered recessive gene, there is one in four chances of 
offspring will have the deafness and two in four chances will be carrier and in $25 \%$ chances child will not be even carrier.

2. Autosomal dominant If altered copy of gene is dominant it can lead to deafness in spite other copy of gene functioning normally and out of such genes some may be resulting in late onset deafness. If one of the parent carries a dominant altered gene, there is a $50 \%$ chance of the children will inherit the disease.

3. X linked inheritance When altered gene is located on $\mathrm{X}$ chromosome in a women and if the second copy gene is normal she will be carrier but in man because of having only one $\mathrm{X}$ chromosome child will be suffering from deafness hence $X$ linked recessive condition affects more often to male and usually result in more profound deafness but if the faulty gene on $\mathrm{X}$ chromosome is dominant then disease may prevail in both male and female children. In about $1 \%$ non syndromic genetic deafness is due to faulty genes on $\mathrm{X}$ chromosome.

4. Mitochondrial inheritance Mitochondria are like a powerhouse. Stretch of DNA which generates energy for functioning of the cell, each cell contains many mitochondria and present in the mother, hence transmitted by the mother only and inherited deafness can not be passed to next generation by father.

The genetic deafness depends on the location of the faulty gene that is located on a chromosome, in the nucleus of the cell or on the mitochondrial DNA and also on whether one or both the copies of the gene are faulty (mutation).

The genetic counseling is going to help the family by clarifying whether the origin of deafness is due to genetic factor or environmental factor. In United States now one percent of the babies are born with IVF and all over the world IVF centers are providing facility of pre-implantation genetic diagnosis.

Pre-implantation genetic diagnosis (PGD) was first reported in 1990 [1]. Pre-implantation genetic diagnosis is the genetic testing of the embryos procured through invitro fertilization by cell biopsy genetic analysis. The test may also include chromosomal analysis or DNA analysis to detect specific gene mutation [2]. PGD was initially developed to have a baby free of genetic disease. In this procedure only one cell is removed. Procedure is almost safe, harmless, non invasive and ethically acceptable procedure. Though data are incomplete on long term health effect of IVF babies [3, 4] but 5,000 PGD cycles have been performed and the incidence of abnormalities is equivalent to the general population $[5,6]$.

More than one hundred genes are available associated with genetic deafness. Powerful genetic testing tools known as microarrays permit multiple gene tests to be performed at one time [7]. The gold standard for molecular PGD analysis is the use of linked polymorphic markers in combination with mutation specific analysis [8]. One must know the longer the gene as MY015 the more it is difficult and expensive to develop and perform the genetic test. Connexin 26 gene also known as CX26, DFNA3, DFN82 or GJB2 is a protein that forms channels to regulate the passage of potassium ions in and out of the cells of the cochlea. This is the gene accounting for more than $70 \%$ non syndromic recessive deafness and can be routinely being tested. A study conducted by Nayyar et al. [9] established the role of PCR RFLP as a cheap and reproducible method for the analysis of CX26W 24X gene mutation, which has been observed as most common (95\%) [10].

For quite sometime genetic centre were performing genetic testing through prenatal genetic testing, amniocentesis and chorionic villous sampling but the final outcome is not very certain, one may predict about the deafness but termination of pregnancy (MTP) is a difficult, social and ethical issue while discarding a non-implanted embryo is not that problematic, and as per federal regulations embryos are not considered human subject [11].

Fluorescent in situ hybridization (FISH), polymerase chain reaction and haplotyping are the most commonly used technologies, FISH is used for the detection of chromosomal abnormalities and PGD for monogenic disorders, pre-implantation haplotyping is a latest and developed in 2006 and uses DNA fingerprinting rather than actual genetic signature (such as point mutations) [12].

There is always co-morbidity after cochlear implantation and the child/person remains handicapped. The cost of each cochlear implant is from 4 lakh to 10 lakh rupees plus life long rehabilitation. The success rate of majority of IVF centre is around 25-35\% [13]. Even after PGD and implantation the average cost of each IVF cycle is around half of a lakh rupee which can be further reduced by $50 \%$ if the drugs are purchased in bulk on advance payment by Government directly from Pharma companies. Thus we shall be having a normal healthy hearing child. Hence in time to come we have to screen the families of the genetically affected deaf person, mainly autosomal dominant for IVF and those prone to environmental factors must be counseled to prevent deafness in next generation.

There are still many genes for which genetic testing is not available hence test result will be negative. With increase in health infrastructure deafness of infective and/or environmental origin is decreasing while but that due to hereditary causes of hearing will persist. Over viewing benefits of PGD I conclude the national deafness programme should be divided in screening, preventing and curing conductive 
hearing loss along with identification of genetic deafness and counseling them to achieve reduced number of sensoneural deafness. At last Public must be made aware of side effect of noise pollution, tobacco chewing and consanguinity. As in India consanguineous marriages are still common which lead to further increased chances of expression of autosomal recessive causes, leading to congenital deafness. Orientation courses for obstetrician and pediatrician are must to screen, prevent and treat antenatal and neonatal deafness and sooner or late gene therapy approaches may come to treat the deafness it self. Sooner or later gene therapy a future hope may treat the deafness itself.

\section{References}

1. Baruch S (2005) Genetic testing of embryos: a critical need for data. Reprod Biomed Online 11:667

2. Kakourou G, Dhanjal S, Daphnis D, Doshi A, Nuttall S, Gotts S (2007) Preimplantation genetic diagnosis for myotonic dystrophy type 1: detection of crossover between the gene and the linked marker APOC2. Prenat Diagn 27:111-116

3. Nayot D (2009) Severe ovarian hyperstimulation syndrome. In: The textbook of assisted reproductive techniques, supra note 23 , pp 645-654; Orvieto R, Ben-Rafael Z (2009) Bleeding, severe pelvic infection, and ectopic pregnancy. In: The textbook of assisted reproductive techniques, supra note 23, pp 655-662

4. President's Council on Bioethics, Reproduction and Responsibility (2004) The regulation of new biotechnologies, pp 94-95. Available at http://www.bioethics.gov/reports/reproductionandres ponsibility/chapter3.html
5. Patki A (2010) Preimplantation genetic diagnosis. Advanced infertility management. FOGSI Focus, pp 146-155

6. International Working Group on Preimplantation Genetics, International Congress of Human Genetics (2001) Preimplantation genetic diagnosis: experience of three thousand cycles. Report of the 11th annual meeting of International Working Group on Preimplantation Genetics, in association with 10th International Congress of Human Genetics, Vienna, May 2001

7. Baruch S (2008) Preimplantation genetic diagnosis and parental preferences: beyond deadly disease. Houst J Health Law Policy 245-268. ISSN 2/17/2009

8. Verlinsky Y, Cohen J, Munne S, Gainaroi L, Simpson JL, Ferraretti AP et al (2004) Over a decade of experience with preimplantation genetic diagnosis. Fertil Steril 82:302-303

9. Nayyar SS, Mukherjee S, Moorchung N, James E, Venkatesh MD, Sukthankar PS, Sabarigirish K, Batra RB (2011) Connexin 26 mutations in congenital SNHL in Indian population. Indian J Otol 17:154-157

10. Ram Shankar M, Girirajan S, Dagan O, Ravi Shankar HM, Jalvi $\mathrm{R}$, Ranghasayee R et al (2003) Contribution of connexin 26 (GJB2) mutations and founder effect to non-syndromic hearing loss in India. J Med Genet 40:e68

11. Office for Human Research Protection Guide for investors and Institutional Review Boards Regarding Research Involving Human Embryonic Stem Cell Germ and stem Cell-Derived Test articles (19 Mar 2002)

12. Renwick PJ, Trussler J (2006) Proof of prinviple and first cases using preimplantation genetic haplotyping - a paradigm shift for embryo diagnosis. Reprod Biomed Online 13(1):110-119

13. Altarescu G, Eldar-Geva T, Brooks B, Zylber-Haran E, Varshaver I, Margalioth EJ, Levy-Lahad E, Renbaum P (2009) Preimplantation genetic diagnosis (PGD) for nonsyndromic deafness by polar body and blastomere biopsy. J Assist Reprod Genet 26(7):391-397. doi:10.1007/s10815-009-9335-5 